\title{
Clinical and Epidemiological Profiles of Patients Admitted to a Pediatric Cardiac Intensive Care Unit
}

\author{
Juciane Rocha Guimarães ${ }^{(1)}$ and Isabel Cristina Britto Guimarães ${ }^{(1)}$ \\ Universidade Federal da Bahia, Salvador, BA - Brazil
}

\section{Abstract}

Background: Congenital and acquired heart diseases are important causes of morbidity and mortality in children. In critical congenital heart defects, when treatment is not adequate, clinical manifestations may lead to death in the neonatal period.

Objective: To establish the clinical and epidemiological profile of patients admitted to the pediatric cardiac intensive care unit (UTI) in a tertiary hospital.

Methods: This was a cross-sectional study conducted from January 2013 to December 2014, based on analysis of patients' medical records. The study sample was composed of 307 children and adolescents with congenial and acquired heart diseases. The score Risk Adjustement for Congenital Heart Surgery 1 (RACHS-1) was used for categorization of the various surgical procedures. Descriptive statistics were calculated using the Satistical Package for Social Sciences (SPSS). Categorical variables were compared using the Pearson's chi-square test, considering a level of significance of $5 \%$.

Results: There was a predominance of patients aged between 28 days and one year (44\%). Congenital heart diseases (91.9\%) prevailed over acquired heart diseases (8.1\%). Extracorporeal circulation was used in 138 patients who underwent surgical procedures, lasting from 12 to 261 minutes. Most patients $(88.9 \%)$ were discharged from the ICU and $11.1 \%$ died. Using the score RACHS-1, corrective cardiac surgery was performed in $75.8 \%$ and paliative surgery in $24.2 \%$ of the patients.

Conclusions: Patients aged between 28 days to one year, with cyanotic congenital heart disease, undergoing cardiac surgery with extracorporeal circulation duration longer than 120 minutes are at a higher risk of death. (Int J Cardiovasc Sci. 2020; 33(4):331-336)

Keywords: Heart Defects, Congenital/Surgery; Epidemiology; Intensive Care Units, Pediatric; Heart Septal Defects/ Surgery; Heart Septal Defects, Ventricular/Surgery.

\section{Introduction}

During embryonic period, cardiac chambers are formed from the cardiac tube division, and interaction of cardiovascular system is defined. During this process, some diseases may appear and progress to death or abnormalities, many of them soon after birth. ${ }^{1}$ Congenital heart diseases are described as defects in the structure of the heart that is present at birth, caused by failure of heart formation after conception or between the eight and tenth week of gestation. ${ }^{2}$

Congenital heart diseases can be classified according to pulmonary flow. Obstructive acyanotic heart defects with normal flow include coarctation of the aorta, interrupted aortic arch, aortic stenosis, mitral stenosis and pulmonary stenosis. Acyanotic heart defects with pulmonary hyperflow and left-to-right shunt include interventricular communication (IVC), interatrial communication (IAC),

Mailing Address: Juciane Guimarães

Av. Reitor Miguel Calmon, s/n. Postal Code: 40110-100, Vale do Canela, Salvador, BA - Brazil.

E-mail: juci.guima@hotmail.com, isabelcbguimaraes@gmail.com 
persistent arterial channel (PAC), atrioventricular septal defect (AVSD) and aorta-pulmonary window. Cyanotic congenital heart defects include decreased pulmonary flow and obstructive diseases with right-to-left shunt: tetralogy of Fallot, tricuspid atresia, pulmonary atresia with or without IVC, transposition of the great arteries (TGA) with pulmonary stenosis (PS), Enstein anomaly, TGA without IVC, hypoplastic left heart syndrome (HLHS), total anomalous pulmonary venous return (TAPVR), and complex heart diseases with PS. Cyanotic cardiac defects with normal flow and parallel circulation include TGA with IVC and common arterial trunk, mitral atresia, and complex heart diseases without PS are classified as cyanotic cardiac defects with pulmonary hyperflow and arteriovenous malformations. ${ }^{3}$

Fetal echocardiography is an imaging test that has been used for the diagnosis of cardiac malformations. However, this test is not performed in all pregnant women, and complex heart diseases related to the arterial channel may not be detected by obstetric ultrasound. ${ }^{4}$ In this regard, pulse oximetry has been recommended by the American College of Cardiology and the American Academy of Pediatrics since 2009 as the screening method for critical congenital heart diseases. ${ }^{5,6}$

In Brazil, it is estimated that 28 thousand new cases of congenital heart diseases are diagnoses per year. ${ }^{7}$ Eighty percent of children with cardiac problems at birth will need some type of intervention. ${ }^{2}$ Considering the number of surgical interventions required and the number of procedures actually performed, there has been a deficit of $65 \%$, especially in the North and Northeast regions, with deficits of $93.5 \%$ and $77.4 \%$, respectively. ${ }^{8}$

Rheumatic carditis, the most common complication of rheumatic fever, is one of the most common heart diseases acquired during childhood in the world, and has been considered the main cause of heart disease among children in developing and developed countries. ${ }^{9-13}$

The objective of the present study was to determine clinical and epidemiological profile of patients admitted to a pediatric cardiac intensive care unit (ICU) of a tertiary hospital in Salvador city, Brazil. This could be used as a basis by tertiary care units to adapt to these conditions and for the development of governmental policies aimed at improving the health of children and adolescents with heart diseases.

\section{Methods}

This was a retrospective, cross-sectional study, based on analysis of medical records of patients admitted to a pediatric cardiac ICU of a tertiary hospital in Salvador, Brazil, during the period from January 2013 to December 2014.

A total of 367 medical records of patients aged between 0 and 15 years, with diagnosis of congenital and acquired heart diseases, were included. Sixty medical records had incomplete admission or discharge forms and were excluded.

Data were collected from the medical records using a specific form that included personal data (age, sex, nutritional status calculated by Z-score), place of origin, clinical and surgical diagnosis, treatment, time of extracorporeal circulation (ECC) and length of stay at the ICU.

Patients with congenital heart diseases undergoing surgical intervention were classified using the Risk Adjusted Classification for Congenital Heart Surgery 1 (RACHS-1), which is an adjusted risk score for surgeries in congenital heart diseases, developed by Jenkins et al. ${ }^{14}$ This instrument allows categorization of several surgical procedures that have similar hospital mortality into six levels.

This study was approved by the ethics committee of the Hospital Ana Nery de Salvador/Bahia.

\section{Statistical analysis}

The variables of the study (age, sex, nutritional status, place of origin, diagnosis, time of ECC, treatment and hospital mortality) were presented in RACHS-1 categories and expressed as numbers and percentages. For the variables: length of hospitalization, time of ECC and age, mean and standard deviation were also calculated. Results were described in tables.

All data were inserted into a database constructed using the Epidata 3.1 software and then transferred to the SPSS software version 20. To determine possible factors associated with hospital mortality, we used the Pearson's chi-square Test. Adjusted association measures (odds ratio) were obtained by logistic regression model, and the level of statistical significance was set at $5 \%$.

\section{Results}

A total of 367 patients were admitted to the pediatric cardiac ICU during January 2013 and December 2014, and 307 were included in the study (Table 1). Distribution of the types of treatment by congenital heart diseases is described in Table 2. 
Table 1 - Distribution of 307 patients admitted to a pediatric cardiac intensive care unit by demographic and nutritional profile and heart disease (2013-2014)

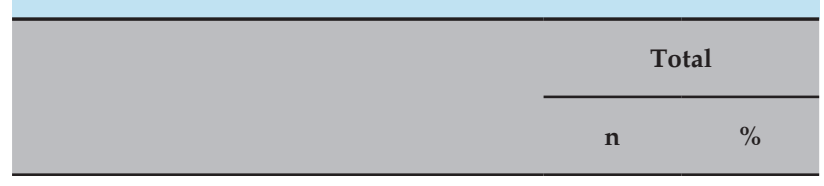

Sex

Female

Male

Origin

Capital

Countryside

108

199

35.2

Age (mean $3.10 \pm 4.10$ )

$<28$ days

$>28$ days -1 year

$>1-5$ years

$>5-10$ years

$>10$ years

Total

146

161

47.6

52.4

Nutritional status

Underweight (Z-score $<-3$ )

Wasting (Z-score $\geq-3$ and $<-2$ )

Normal (Z-score $\geq-2$ and $<+1)$

Overweight ( $Z$-score $\geq+1$ and $<+3$ )

Diagnosis of heart disease

Acquired

Rheumatic

Congenital

Acyanotic

Cyanotic

The most common diagnoses of acyanotic heart defects were IVC (24.5\%), followed by total AVSD (19.9\%), PAC and IAC (13.2\% each), coarctation of the aorta $(11.9 \%)$, partial AVSD (7.3\%), pulmonary valve stenosis (PVS) $(4.6 \%)$, aortic stenosis $(4 \%)$, and double outlet right ventricle (DORV) + subaortic IVC (1.3\%). Among the cyanotic congenital heart defects, the most common was tetralogy of Fallot $(30 \%)$, followed by tricuspid atresia $(17.6 \%)$, complex heart diseases $(15.3 \%)$, pulmonary atresia $(9.9 \%)$, TGA $(9.2 \%)$, DORV + PS (6.1\%), TAPVR
Table 2 - Frequency of therapeutic treatments for acquired and congenital heart diseases in 307 patients admitted to a pediatric cardiac intensive care unit (2013-2014)

\begin{tabular}{|c|c|}
\hline Heart diseases & $\mathbf{n}$ \\
\hline \multicolumn{2}{|l|}{ Acquired } \\
\hline Clinical & $9(35 \%)$ \\
\hline Surgery & $13(52 \%)$ \\
\hline Mitral valve replacement & $5(38.5 \%)$ \\
\hline Double valve replacement ${ }^{*}$ & $3(23 \%)$ \\
\hline Mitral valve repair & $5(38.5 \%)$ \\
\hline Percutaneous & $3(12 \%)$ \\
\hline Mitral valvuloplasty & $2(66.7 \%)$ \\
\hline Aortic valvuloplasty & $1(33.3 \%)$ \\
\hline \multicolumn{2}{|l|}{ Congenital } \\
\hline Clinical & $74(26.2 \%)$ \\
\hline Surgery & $190(67.4 \%)$ \\
\hline Total repair & $144(75.8 \%)$ \\
\hline Palliative repair & $46(24.2 \%)$ \\
\hline Percutaneous & $18(6.4 \%)$ \\
\hline Pulmonary valvuloplasty & $14(77.8 \%)$ \\
\hline Aortic valvuloplasty & $1(5.6 \%)$ \\
\hline Balloon atrioseptostomy & $3(16.7 \%)$ \\
\hline
\end{tabular}

(6.1\%), single ventricle and truncus arteriosus (2.3\% each) and Enstein anomaly (0.8\%).

Among children and adolescents with complications of surgical repair $(\mathrm{n}=94), 64.3 \%$ had hemodynamic complications, $33.3 \%$ had infection, $27.2 \%$ coagulation disturbances, $14 \%$ arrythmias, $6.5 \%$ renal complications, $6.5 \%$ procedural complications, and 3,2\% neurological complications.

ECC was used in 138 patients; duration of ECC was $<90$ minutes in 52.2\%, 90-120 minutes in 21\%, and $>120$ minutes in $26.8 \%$. Mean time of ECC was $95.2 \pm 53.7$ minutes, varying from 12 to 261 minutes.

Mean length of stay at the ICU was $9.7 \pm 16.4$ days, varying from one to 181 days. ICU length of stay was $<7$ days for $73.3 \%$ of patients, $8-15$ days for $15.3 \%$ and $>15$ days for $11.4 \%$. 
Of 307 patients, $11.1 \%$ died and $88.9 \%$ were discharged from the ICU. Cardiogenic shock was the cause of $61.8 \%$ of deaths, followed by septic shock $(35.5 \%)$ and coagulation disturbances $(2.9 \%)$.

A robust association was found between age and death $(p=0.001)$ (Table 3$)$. The type of heart disease $(p=0.004)$ and the use of ECC were also associated with hospital mortality; however, after logistic modelling, only age (adjusted $\mathrm{OR}=2.706 ; \mathrm{p}=0.001$ ) and diagnosis of congenital heart diseases (adjusted $\mathrm{OR}=0.363$; $p=0.001$ ) were associated with hospital mortality. Bivariate analysis was not performed for acquired heart diseases, as they constituted only one category, which made the crossing of data impossible.

The RACHS-1, adjusted for congenital heart diseases, was used in 190 patients. In category 1 (21.1\%), the most frequent were PAC (43.6\%) and IAC (41\%) surgical treatments. In category $2(50 \%)$, the total surgical repair of tetralogy of Fallot (35.7\%) was the most common procedure. In category $3(44.9 \%)$, the systemic-topulmonary shunt (modified Blalock-Taussig shunt) was the most common procedure (33.7\%), and in category 4 $(13 \%)$, Rastelli operation (30.8\%) was the main procedure. No intervention was classified as category 5 or 6 .

The highest percentage of deaths (38.5\%) occurred in category 4 , as described in Table 4 .

\section{Discussion}

The present study evidenced a high prevalence of children coming from the countryside of Bahia state. This is probably due to a lack of specialized services in pediatric cardiology for an early diagnosis and treatment of these patients in the cities of origin. Previous studies corroborate this finding. ${ }^{15-19}$ The predominance of men and infants younger than one year was also similar to previous studies. . $^{15,16,19-22}$

In developed countries, Kawasaki disease is the main cause of acquired heart disease, notably in Japan and in the USA, with incidence varying from 3 to 112 per 100,000 children younger than five years old. ${ }^{9}$ In underdeveloped and developing countries, rheumatic carditis is the main cause of acquired heart disease, as in Brazil. ${ }^{10-12}$ In the present study, acquired heart disease accounted for $8.1 \%$, with rheumatic heart disease as the main cause. Similar results were reported by Miyague et al. ${ }^{23}$

In the study population, heart valve lesions accounted for $52 \%$ of rheumatic heart diseases treated surgically,
Table 3 - Frequency of deaths in patients admitted to a pediatric cardiac intensive care unit by age, sex, nutritional profile (Z-score), diagnosis, treatment and extracorporeal circulation time (2013-2014)

\begin{tabular}{|c|c|c|}
\hline \multirow[b]{2}{*}{ Category } & \multicolumn{2}{|c|}{ Deaths $(n=34)$} \\
\hline & $\begin{array}{c}\text { Yes } \\
\text { n (\%) }\end{array}$ & $\begin{array}{c}\text { No } \\
\text { n (\%) }\end{array}$ \\
\hline
\end{tabular}

Age $(\mathrm{n}=307)$

$<28$ days

$7(20.6 \%) \quad 19(7.0 \%)$

$>28$ days and $\leq 1$ year

$21(61.8 \%)$

$114(41.8 \%)$

$>1$ year $\leq 5$ years

$5(14.7 \%)$

$43(15.8 \%)$

$>5$ years

$1(2.9 \%)$

$97(31.9 \%)$

0.001

$\operatorname{Sex}(n=307)$

Female

$15(44.1 \%) \quad 131(48.0 \%)$

Male

$19(55.9 \%) \quad 142(52.0 \%)$

0.670

BMI for age (Z score) $(n=307)$

Underweight

$13(38.2 \%)$

$95(34.8 \%)$

Wasting

$5(14.7 \%)$

$56(20.5 \%)$

Normal

$14(41.2 \%)$

$90(33.0 \%)$

0.542

Overweight

$2(5.9 \%)$

$32(11.7 \%)$

Diagnosis $(n=307)$

$\begin{array}{lccc}\text { Acquired heart disease } & 2(5.9 \%) & 23(8.4 \%) & \\ \text { Congenital heart } & 32(94.1 \%) & 250(91.6 \%) & 0.609\end{array}$

Congenital heart disease $(n=282)$

$\begin{array}{llll}\text { Acyanotic } & 10(31.2 \%) & 141(56.4 \%) & 0.007 \\ \text { Cyanotic } & 22(68.8 \%) & 109(43.6 \%) & \end{array}$

Treatment $(n=307)$

Acquired heart disease $(n=25)$

$\begin{array}{lccc}\text { Clinical } & 1(50 \%) & 8(34.8 \%) & \\ \text { Surgical } & 0(0 \%) & 13(56.5 \%) & 0.145 \\ \text { Percutaneous } & 1(50 \%) & 2(8.7 \%) & \end{array}$

Congenital heart disease $(n=282)$

$\begin{array}{lccc}\text { Clinical } & 11(34.4 \%) & 63(25.2 \%) & \\ \text { Surgical } & 20(62.5 \%) & 170(68.0 \%) & 0.441 \\ \text { Percutaneous } & 1(3.1 \%) & 17(6.8 \%) & \end{array}$

ECC time $(n=138)$

$\begin{array}{lll}<90 \text { minutes } & 4(23.5 \%) & 68(56.2 \%) \\ 90-120 \text { minutes } & 4(23.5 \%) & 25(20.7 \%) \\ >120 \text { minutes } & 9(52.9 \%) & 28(23.1 \%)\end{array}$

BMI: body mass index; ECC: extracorporeal circulation; $\left({ }^{*}\right)$ Pearson's chi-square test; $p$-values $<0.05$ were considered statistically significant. 


\begin{tabular}{|c|c|c|}
\hline RACHS-1 & $\begin{array}{c}\text { Observed } \\
\text { mortality } \\
\text { n (\%) }\end{array}$ & $\begin{array}{c}\text { Expected } \\
\text { mortality } \\
(\%)^{*}\end{array}$ \\
\hline Category 1 & $2(5.1)$ & 0.4 \\
\hline Category 2 & $2(4)$ & 3.8 \\
\hline Category 3 & $11(13.3)$ & 9.5 \\
\hline Category 4 & $5(38.5)$ & 19.4 \\
\hline
\end{tabular}

$35 \%$ of the cases treated clinically and $12 \%$ of those undergoing percutaneous procedures. Valvuloplasty and mitral valve replacement accounted for most of the procedures. According to Muller, ${ }^{10}$ the mitral valve is affected in most cases of rheumatic carditis, while aortic valve lesions are present in approximately $30 \%$ of the cases. In our study, $23 \%$ of patients with rheumatic heart disease treated surgically underwent double valve replacement. No case of pulmonary or tricuspid valve disease was reported, corroborating the findings of this author ${ }^{10}$ who described that lesions related to these both valves have transient anatomic features in the acute phase, corresponding to an estimated $5 \%$ of the cases.

The most common diagnosis among acyanotic heart defects was IVC (24.7\%), similar to previously reported by Aragao et al., $(21 \%)^{17}$ and Miyague et al., (30.5\%). ${ }^{23}$ These same authors reported the prevalence of $7.7 \%$ and $19.1 \%$ for IAC and $18 \%$ and $17 \%$ for PAC, respectively. We found a prevalence of $13.2 \%$ of these conditions. Tetralogy of Fallot was the most frequent cyanotic congenital heart disease $(32.1 \%)$, corroborating the studies by Miyague et al. $(9.9 \%),{ }^{23}$ Borges et al. $(8.1 \%)^{16}$ and Aragao et al. $(14 \%),{ }^{18}$ but contrasting with the findings of Nina et al., ${ }^{21}$ describing the presence of this anatomical malformation in only $4 \%$ of the patients.

With respect to mortality rate in the study group $(11.1 \%), 0.65 \%$ of deaths were related to acquired heart diseases, mostly $(10.35 \%)$ congenital heart defects. This is similar to that reported by Guitti ${ }^{15}(10 \%)$ and lower than the percentage reported by Nina et al. (17.2\%).

Regarding the RACHS-1 score, although $44.9 \%$ of the patients were classified in category 3 , mainly those undergoing palliative surgeries (33.7\%) related to the systemic-to-pulmonary shunt (modified Blalock-Taussig shunt), the highest mortality was found in category 4 (38.5\%) followed by category 3 (13.3\%). In agreement with Jenkins et al., ${ }^{14}$ the higher the risk category, the higher the mortality. Similar findings were reported in national and international studies. ${ }^{19,21,22,24}$

In our study group, mortality predictors were infants aged between 28 days and one year (61.8\% of deaths, $\mathrm{p}=0.001$ ), diagnosis of cyanotic congenital heart disease (68.8\% of deaths, $\mathrm{p}=0.007)$ and time of extracorporeal circulation greater than 120 minutes $(52.9 \%, p=0.018)$.

Comparisons of these findings with other tertiary care centers would provide information that may serve as a basis for a more detailed knowledge of these patients' profile, and development of indicators to guide the prediction of technological support and reassessment of processes, contributing to the performance in these centers.

Limitations of these studies were those expected and inherent to cross-sectional designed studies, particularly those related to data collection. There were no electronic medical records, which made it difficult to identify some clinical variables, such as age, body weight and medical history of the patients. The scarcity of the literature on the application of the RACHS- 1 was another limitation.

\section{Conclusion}

Congenital heart diseases were more prevalent than acquired heart diseases. Surgical treatment was the main reason of admission of the children to the pediatric cardiac ICU. Total repair surgeries were more prevalent than palliative surgeries. Hemodynamic complications were more commonly seen in patients undergoing surgical interventions. In this study, patients with cyanotic congenital heart diseases, aged between 28 days and one year, undergoing surgical treatment, with extracorporeal circulation duration longer than 120 minutes are at higher risk of death. Although most patients were classified as risk category 3 in the RACHS-1 score, the highest mortality rate was associated with risk category 4 .

\section{Author contributions}

Conception and design of the research: Guimarães JR. Acquisition of data: Guimarães JR. Analysis and interpretation of the data: Guimarães ICB. Statistical analysis: Guimarães JR. Writing of the manuscript: 
Guimarães JR, Guimarães ICB. Critical revision of the manuscript for intellectual content: Guimarães ICB.

\section{Potential Conflict of Interest}

No potential conflict of interest relevant to this article was reported.

\section{Sources of Funding}

There were no external funding sources for this study.

\section{Study Association}

This article is part of the thesis of master submitted by Juciane Rocha Guimarães, from Universidade Federal da Bahia.

\section{Ethics approval and consent to participate}

This article does not contain any studies with human participants or animals performed by any of the authors.

\section{References}

1. Sampaio AC, Azambuja AP, Xavier Neto J, Lopes LM, Costa SMS VM. Embriogenia cardiovascular. In: Croti UA, Mattos S da S, Pinto Junior VC, Aiello VD, eds. Cardiologia e Cirurgia Cardiovascular Pediátrica. 2a.ed. São Paulo: Roca; 2012. p.28-46.

2. American Heart Association (AHA). About Congenital Heart Defects. Dallas. [Internet]. \{Cited in 2018 june 11]. Available from:http:// www.heart.org/HEARTORG/Conditions/ CongenitalHeartDefects/ AboutCongenitalHeartDefects/AboutCongenitalHeartDefects UCM_001217_Article.jsp\#.Wx6b2yAnbIU.

3. Mattos SS, Croti UA, Pinto Júnior VC, Moreira VM, Aiello VD. Croti UA, Mattos SS, Pinto Junior VC AV. Terminologia e classificação didática das cardiopatias congênitas. In: Croti UA, Mattos S da S, Pinto Junior VC, Aiello VD, eds. Cardiologia e Cirurgia Cardiovascular Pediátrica. 2a. ed. São Paulo: Roca; 2013. p:99-118

4. Hoffman JIE, Kaplan S. The incidence of congenital heart disease. J Am Coll Cardiol. 2002;39(12):1890-900

5. Mahle WT, Newburger JW, Matherne GP. Role of pulse oximetry in examining newborns for congenital heart disease: A scientific statement from the American Heart Association and American Academy of Pediatrics. Circulation. 2009;120(5):447-58

6. Sociedade Brasileira de Pediatria (SBP). Diagnóstico Precoce de Cardiopatia Congenita Crítica: Oximetria de Pulso Como Ferramenta Da Triagem Neonatal. 2011. [Acesso 2017 junho 10]. Disponível em: http:// www.sbp.com.br/pdfs/diagnostico-precoce-oximetria.pdf.

7. Silva MEM Da, Feuser MR, Silva MP, Uhlig S, Parazzi P, Rosa G,et al.Pediatric cardiac surgery: what to expect from physiotherapeutic intervention? Rev Bras Cir Cardiovasc. 2011;26(2):264-72

8. Pinto Jr VC, Daher CV, Sallum FS, Jatene MB, Croti UA. The situation of congenital heart sugeries in Brazil. Rev Bras Cir Cardiovasc 2004; 19(2):III-VI

9. Heuclin T, Dubos F, Hue V, Godart F, Francart C. Increased Detection Rate of Kawasaki Disease Using New Diagnostic Algorithm, Including Early Use of Echocardiography. J Pediatr. 2009;155(5):695-700.

10. Muller RM. O difícil diagnóstico diferencial entre atividade e cardite reumática. Rev SOCERJ. 1996:9(1):38-40.

11. Moretti MA; Ferreira Cardiologia Prática. São Paulo: Atheneu; 2010.

12. Benjamin EJ, Virani SS, Callaway CW, et al. Heart Disease and Stroke Statistics - 2018 Update: A Report From the American Heart Association Circulation. 2018;137(12):e67-e492

13. Sociedade Brasileira de Cardiologia, Sociedade Brasileira de Pediatria, Sociedade Brasileira de Reumatologia. Diretrizes Brasileiras para o Diagnóstico , Tratamento e Prevenção da Febre Reumática. Arq Bras Cardiol. 2009;93(3 (supl.4)):1-18.

14. Jenkins KJ, Gauvreau K, Newburger JW, Spray TL, Moller JH, Iezzoni LI. Consensus-based method for risk adjustment for surgery for congenital heart disease. J Thorac Cardiovasc Surg. 2002;123(1):110-8.

15. Guitti JCDS. Aspectos Epidemiológicos das Cardiopatias Congénitas em Londrina, Paraná. Arq Bras Cardiol. 2000;74(5):395-9.

16. Borges D. Complicações pulmonares em crianças submetidas à cirurgia cardíaca em um hospital universitário. Rev Bras Cir Cardiovasc. 2010;25(2):234-7.

17. Magalhães Filho J. Cardiopatia reumática em crianças e adolescentes: aspectos demograáficos, epidemioloógicos, clínicos e ciruúrgicos num hospital público de referência em Salvador - Bahia.(dissertação). Salvador/Bahia;2012.

18. Aragão J, Mendonça M, Silva M, Moreira A, Aragão M, Reis F. O Perfil Epidemiológico dos Pacientes com Cardiopatias Congênitas Submetidos à Cirurgia no Hospital do Coração. Rev Bras Ciênc Saúde. 2013;17(3):263-8.

19. Bastos LF, Araújo TM de, Caetano JA. Clinical and Epidemiological Profile of Children With Congenital Heart Disease Submitted To Cardiac Surgery. Rev Enferm UFPE. 2013;7(8):5298-304 7.

20. Oliveira JMA de, Silva AMF, Cardoso S de B, Ferreira FL, Zierer M de S, Carvalho ML. Complicações no pós-operatório de cirurgia cardiovascular com circulação extracorpórea. RIES. 2015;8: 9-15.

21. Nina RV de AH, Gama MEA, Santos AM Dos, Nina V, Figueiredo Neto JA, Mendes UG O escore de risco ajustado para cirurgia em cardiopatias congênitas (RACHS-1) pode ser aplicado em nosso meio? Rev Bras Cir Cardiovasc. 2007;22(4):425-31

22. Larsen SH, Pedersen J, Jacobsen J, Johnsen SP, Hansen OK, Hjortdal V. The RACHS-1 risk categories reflect mortality and length of stay in a Danish population of children operated for congenital heart disease. Eur J Cardio-thoracic Surg. 2005;28(6):877-81.

23. Miyague NI, Cardoso SM, Meyer F, Ultramani FT, Araujo FM, Rozkowisk I, et al. Estudo Epidemiológico de Cardiopatias Congénitas na Infância e Adolescência. Arq Bras Cardiol. 2003;80(3):269-73.

24. Kang N, Cole T, Tsang V, Elliott M, De Leval M. Risk stratification in paediatric open-heart surgery. Eur J Cardio-thoracic Surg. 2004;26(1):3-11. 